\section{RUSSELL'S NATURALISTIC TURN}

\author{
Ned S. Garvin \\ Philosophy / Albion College \\ Albion, MI 49224
}

\section{INTRODUCTION}

$\mathrm{I}$

n 1943 Bertrand Russell wrote a little-known, three-page document he titled "Project of Future Work". It outlines the descriptive project of examining non-demonstrative inference that eventually becomes the focal point of Human Knowledge: Its Scope and Limits. More remarkably, this document anticipates many salient features of naturalized epistemology, e.g., Russell argues that ( $\mathrm{r}$ ) an answer to scepticism is futile, we cannot justify scientific method; (2) the Humean Predicament arises from a traditional insistence on an unrealistic, demonstrative canon of justification; (3) non-demonstrative, fallible inference is already firmly embedded in scientific practice as a canon of inference, and should augment the demonstrative canon; and (4) the primary epistemic problem is descriptive: in what circumstances does scientific method allow us to infer the existence of something unobserved from what we observe. These claims, in the wake of An Inquiry into Meaning and Truth, suggest that Russell was on the verge of his own naturalistic turn. I argue that, despite striking anticipations of naturalized epistemology, Russell develops his descriptive project within a more traditional, critical epistemic perspective.

\section{RUSSELL'S NATURALISTIC TURN}

W. V. Quine's address to the Fourteenth International Congress of Philosophy in 1968, published a year later as "Epistemology Naturalized" in Ontological Relativity and Other Essays, is a landmark of recent epistemology, marking the turn from traditional critical epistemology to a descriptive epistemology firmly embedded within natural science.
Quine argued that traditional justification requires non-scientific propositions that are more secure than scientific propositions, and we see there are none: science is providing the best account of the world and our knowledge of it. Though we abandon the attempt to justify science, we still attempt to understand it for nearly the same reasons that always motivated epistemology: "in order to see how evidence relates to theory, and in what ways one's theory of nature transcends any available evidence". ${ }^{\text {. }}$

Russell contemplated a naturalistic turn of his own in 1943, shortly after writing An Inquiry into Meaning and Truth and nearly twentyfive years before Quine's landmark address. In the introduction to his Inquiry Russell claims that there are "two different inquiries, both important, and each having a right to the name 'theory of knowledge" (IMT, p. I2). The first is recognizably natural epistemology:

In the first form of theory of knowledge, we accept the scientific account of the world, not as certainly true, but as the best at present available. The world, as presented by science, contains a phenomenon called "knowing", and theory of knowledge, in its first form, has to consider what sort of phenomenon this is. Viewed from the outside, it is, to begin with, a characteristic of living organisms, which is (broadly speaking) increasingly displayed as the organism becomes more complex. (Pp. 12-13)

Both knowledge and error, at this stage, are observable relations between the behaviour of the organism and the facts of the environment. (P. 14)

Here we have many of the hallmarks of naturalized epistemology: (I) fallibilism, (2) the "best theory" account of science, (3) the view that "knowing" is a natural phenomenon not confined to humans, and (4) the embedding of epistemology in behavioural psychology.

But in 1940 Russell was a foundationalist (though an increasingly moderate one) who insisted that normative, or as he called it, "critical" epistemology must be distinguished from natural epistemology, and that critical epistemology is philosophically more important: "Within its limitations, theory of knowledge of the above sort is legitimate and

\footnotetext{
' Quine, Ontological Relativity (New York: Columbia U. P., 1969), p. 83. ${ }^{2}$ Russell advocated this hypothetical acceptance of science much earlier, e.g., in AMa, pp. 398-9.
} 
important. But there is another kind of theory of knowledge which goes deeper and has, I think, much greater importance" (IMT, p. 14).

Russell observes that behavioural psychologists omit that they are fallible observers, and this fallibility introduces doubt into their results. Further, naive realism, which asserts that we experience objects directly, leads to physics, which asserts that we do not! Reflection on such omissions and inconsistencies prompts us to doubt the results of naturalistic epistemology, and drives us, as it did Descartes, to a more "critical" epistemology $\left(I M T_{2}\right.$, p. I $)$. This critical epistemology has a familiar foundationalist ring:

Epistemology must arrange all our beliefs, both those of which we feel convinced, and those that seem to us only more or less probable, in a certain order, beginning with those that, on reflection, appear to us credible independently of any argument in their favour, and indicating the nature of the inferences (mostly not strictly logical) by which we pass from these to derivative beliefs. $\left(I M T_{2}\right.$, p. I7)

Russell makes one major concession here. The inferences from basic propositions are "not strictly logical", and so deductive logical theory is of no use in clarifying the nature of the inferences to derivative beliefs-except to tell us they are invalid. By the time Russell had finished his lectures, he had made two other concessions: ( $\mathrm{I}$ ) basic propositions, themselves, are not indubitable; and (2) scepticism is unanswerable without non-demonstrative principles of inference: "I am prepared to concede that all data have some uncertainty, and should therefore, if possible, be confirmed by other data" (p. 125); and "Pure empiricism, finally, is believed by no one, and if we are to retain beliefs that we all regard as valid, we must allow principles of inference which are neither demonstrative nor derivable from experience" ( $p$. 305).

Thus, from uncertain foundations we justify, in some unclear sense, the scientific beliefs we are entitled to think are probably true. What one begins to doubt is that foundationalism, weakened in this way, escapes the Humean predicament or manages to be "deeper" than naturalized epistemology pragmatically accepted as the best available theory.

\section{2. "PROJECT OF FUTURE WORK"}

Russell apparently had such doubts shortly thereafter, for in 1943 he claims that the attempt to answer the sceptic and justify science is futile and advocates a project in which he treats scientific method as valid, nearly eclipsing the second, "deeper" form of critical epistemology in favour of natural epistemology:

The situation is this: if we adhere to demonstrative logic, there is no escape from Hume's scepticism. But in fact no one is a sceptic in this sense: even Hume would rather eat bread than a stone. Therefore scepticism is an insincere philosophy. On the other hand, many inferences to which the untrained are prone-especially hasty generalizations-are condemned by accepted scientific method. Thus arises the problem of analyzing scientific method, with a view to formulating the kinds of inference that it allows. In this analysis scientific method would be treated as valid. Details might be questioned, but the attempt to justify it as a whole is futile.

This quotation comes from an unpublished, three-page, typed document in the Russell Archives titled simply: "PROJECT OF FUTURE wORK, Bertrand Russell. (February, I943)". In this document, written while he was finishing the draft of A History of Western Philosophy, Russell notes that his current commitment to the History will occupy him until the end of September 1943 and then declares that he wishes next to "systematize non-demonstrative inference" (p. I). What follows is a brief justification of this descriptive project. His strategy is fascinating, his arguments primarily historical and pragmatic.

He calls attention to two canons of inference, i.e., two sets of standards by which we judge argument rational and justification adequate. The first, our explicit canon of demonstrative inference, developed out of the mathematical argumentation of the early Greeks, was first systematized by Aristotle, and is now formalized in mathematical logic. As we understand it better, we understand its limits: demonstrative inference seldom occurs outside of mathematics. The second, our implicit canon of non-demonstrative inference, is developing out of recent successful scientific practice, and is anything but well under-

\footnotetext{
3 "Project of Future Work" (dated Feb. 1943), RAr 220.017210, p. 2. My italics.
} 
stood or systematized. Yet, some non-demonstrative inference in the natural sciences functions as a canon analogous to deductive logic; it ends controversy about empirical matters as effectively as proofs end controversy about mathematical matters and, as logic, is no more subject to practical questioning.

Russell claims that the Humean predicament results when we use the demonstrative canon to assess general epistemic justification; thus, Russell blames the predicament on a narrow, inappropriate canon of rational argument, satisfaction of which is futile and uninteresting. ${ }^{4}$ No one advocates the severe scepticism that results from an insistence on the demonstrative canon, and so demonstrative justification of science is not a serious philosophical issue. What is important is the systematization of non-demonstrative inferences embedded in our expectations. It is clear that some non-demonstrative inferences are reasonable and reliable, and it is equally clear that some are not; what is not clear is what divides the classes. Thus, the problem of analyzing rather than justifying scientific method arises as a serious epistemic issue. Let's take a closer look.

\section{TWO CANONS OF INFERENCE}

Russell begins his defence with an observation about the systematization of demonstrative inference first in Aristotle's syllogistic logic, and recently in mathematical logic:

This has its importance in mathematics, but outside mathematics demonstrative inference hardly occurs. Every improvement in deductive logic has restricted its scope, and it has appeared that a great deal of traditional philosophy depends upon a fallacious use of deduction. ("Project", p. I)

It is not clear, in this context, just what Russell means by the decreasing scope of deductive logic or the fallacious use of deduction in philosophy, or why these should be important, until he states that

4 Quine calls our inability to justify our claims about physical bodies the "doctrinal side" of the predicament, and our inability to reconstruct object language in perceptual terms the "conceptual side" of the predicament. Russell's concern here is with the doctrinal side.

s. Russell points this out much earlier, e.g., in $A M a$, p. 16, and $I M T_{2}$, p. 303. the Humean predicament results from a deductive conception of reason that is too narrow, and observes: "There is, however, in the practice of science, an implicit canon of inference, which is not demonstrative, in the sense that the conclusion may be false when the premises are true and the reasoning is correct" (ibid.).

Now the strategy becomes clearer. This is an historical reflection on the evolution and use of our standards of argument and evidence-the philosophic canon of rational argument. Aristotelian logic and mathematical logic are systematic endeavours to bring clarity and precision to the natural distinction between good and bad arguments, and to explain what makes good arguments good, and bad arguments bad. The historical origin of this distinction lies in the mathematical argumentation of the early Greeks, and later deductive logical theory directly reflects the character of "good" and "bad" mathematical arguments; respectively, validity and invalidity. But as we use this deductive canon to evaluate our own general argumentation we discover that demonstrative inference hardly occurs outside of mathematics, and arguments we regard as reasonable are invalid by deductive standards. Thus, for an ever-increasing class of arguments we firmly believe are reasonable, deductive logical theory fails to explain what makes good arguments good, and bad arguments bad. This is what Russell means by the restriction of deductive logic's scope: its usefulness diminishes, as a general canon of inference, as we discover that demonstrative inference is atypical. Good, non-demonstrative inferences are "good" in some sense other than that clarified by the deductive concept of validity.

By the fallacious use of deduction Russell seems to refer to rationalist system building and positivist attempts to escape the Humean predicament using only the evidence of the senses and valid forms of inference. These are exposed as invalid, and the attempt futile, by careful logical analysis, analysis such as he carried out in his Inquiry.

The most obvious source of reasonable non-demonstrative inference is physical science. Prima facie, scientific inference is reasonable, effective inference, whose reasonableness and efficacy are inexplicable by demonstrative standards. Judged by the demonstrative canon, scientific justifications of belief are simply invalid, and, if we assume that the demonstrative canon defines reasonableness, unreasonable. To avoid the paradox that science is both reasonable and unreasonable, we must 
modify our beliefs. Either we decide that our prima facie judgment of science was wrong, and dismiss science as unreasonable, or we decide that our demonstrative canon of reasonable argument is too narrow, in order to retain our belief that science is reasonable. Russell suggests that we should take the latter course and deny that the demonstrative canon defines, exclusively, what is reasonable. He suggests two basic reasons for this: (I) science has already established itself as an implicit canon of inference, and (2) the alternative is a scepticism no one accepts.

\section{THE NON-DEMONSTRATIVE CANON}

When Russell says that there is an implicit canon of inference in scientific practice, he means that certain kinds of non-demonstrative arguments are readily accepted as reasonable justifications of our beliefs, serve as paradigm cases of what counts as reasonable, and withstand critical scrutiny as forms of inference. As he puts it:

Empiricists therefore employ a logic which is not that of deduction, but is nevertheless regarded as valid by every practical man of science. Whenever such a man performs a successful experiment, he draws certain inferences from its outcome; it is seldom that the logic employed in drawing these inferences is questioned, and, if it is, the consequent controversy is seldom long. ("Project", pp. I-2)

Russell, no doubt, would have us notice the parallel between the early development of logic out of mathematical argumentation and the current state of scientific argumentation. Empiricists, like mathematicians, have developed a sense of what counts as reasonable argument given their goals and limitations. Their agreement on what counts as reasonable argument constitutes an implicit canon in practice, analogous to that which developed in mathematical disputation before Aristotle, guiding scientific disputation by winnowing reasonable from unreasonable justification, and settling methodological disputes. This general agreement by a reflective subclass of the population is the behavioural evidence that establishes, at least according to natural epistemology, both demonstrative and scientific non-demonstrative inference as proper canons of inference. ${ }^{6}$

${ }^{6}$ Had Russell developed a wholeheartedly naturalistic position, he might have
Russell's point here is historical and pragmatic: scientific practice has become so well entrenched that we do appeal to it to settle factual disputes, we do regard it as a paradigm of rational problem-solving behaviour, it does function as a canon of reasonable argument, and it does not have a serious philosophic rival. What should we do with these facts? From the natural standpoint, at least, we should see that scientific inference is rational behaviour, as firmly embedded as the rational behaviour of early Greek mathematicians. We should widen our concept of "reasonable" to include at least some non-demonstrative inference and proceed to systematize non-demonstrative for the same reasons we systematized deduction. Our failure to do so has generated the Humean predicament.

\section{THE HUMEAN PREDICAMENT}

Russell claims that a traditional insistence on demonstrative reason as the canon of reasonable argument results in a dilemma:

... tradition makes it natural to demand, in an inference, the sort of certainty, in the connection of premises and conclusion, that only deductive arguments can give. Hence arises either scepticism or unreasoning faith. "Reason" being conceived too narrowly, it is thought impossible to be reasonable. ("Project", p. I)

This is a plausible, timely account, especially considering that Russell's analysis was written twenty years before Gettier's famous counter-example to the traditional theory that knowledge is justified true belief. Plato's analysis of knowledge in the Theaetetus suggests that knowledge is true belief plus an account, but he is never able to clarify the sense of "account" needed. It is Aristotle who clarifies "account" with his theory of the syllogism: knowledge claims are justified when they are conclusions of sound syllogisms. Thus, "account" becomes rational argument, and rational argument is demonstrative argument. (Russell's reaction to this in his History is that Greek theory of knowledge suffered from an "over-estimation of deduction" [HWP, p. 199].)

argued that since we have no non-natural, privileged access to truth, this is the best evidence we can expect. 
But, as Russell was well aware, the assumption that validity is the hallmark of proper justification is not limited to ancient Greek philosophy. It dominates philosophy generally, including the epistemic work of many of his contemporaries. ${ }^{7}$ Russell had already argued in the Inquiry that empirical premisses that refer solely to immediate experiences cannot validly imply any scientific or commonsense conclusions that refer to enduring physical objects, causal laws, or other persons, and so if "demonstrative" exhausts the concept of "reasonable", the attempt to justify scientific hypotheses empirically is futile. ${ }^{8}$ Here, then, are Russell's alternatives: (I) scepticism about the external world the other minds, or (2) an unreasoning faith in scientific and commonsense conclusions. 9 The latter would be as repugnant to Russell as the religious dogmatism he avidly condemned, and the former, which he regards as irrefutable in the Inquiry, he dismisses there as "too short and simple to be interesting" (p. I33). In his "Project" it is also insincere. . $^{\circ}$

The alternative of unreasoning faith in science has been abandoned without additional argument, and the choices neatly reduced to scepticism or science. No one, once she understands what it means, accepts the kind of scepticism generated by an insistence on justification of beliefs; and, as we have seen, we already accept scientific practice as a paradigm of reasonable argument and evidence. Russell thinks we should augment the philosophic canon with principles of nondemonstrative inference.

To appreciate Russell's strategy, we might look at his argument as a reductio ad impossibile. Our belief that science is a paradigm of knowledge and our belief that knowledge must be demonstratively justified

7 A classic example written after Russell's diagnosis of the problem is "Studies in the Logic of Explanation", by C. Hempel and P. Oppenheim, Philosophy of Science, Is (1948): 135-75. They specify four necessary conditions for adequate scientific explanation;

8 IMT $\mathrm{PP}$. 303 . This is a stronger position that the one he advocates in $A M a$.

${ }^{8} I M T_{2}$, pp. $303-5$. This is a stronger position that the one he advocates in $A M a$.
9 Russell arrives at these alternatives at least as early as 1927 in $A M a$. Here he considers three alternatives: (I) solipsism, (2) phenomenalism, and (3) the causal theory of perception. He rejects phenomenalism on the grounds that it requires the assumption of causality. $C f$. pp. 398-9.

to See the quotation at the beginning of sec. 2. He makes a similar point in the Inquiry when he says that pure empiricism, finally, "is believed by no one" (p. 305) generate the contradiction that science is knowledge and not. But, this reductio tells us only that we must modify our beliefs, not which beliefs we must modify. That no one sincerely believes scepticism, and virtually everyone sincerely believes that science is a paradigm of reasonable inquiry, are important behavioural evidence that we have made an implicit decision. We have decided that it is our methodological assumption about the scope of reasonable argument, not our ontological assumption of physical bodies, that needs reform.

\section{THE PROJECT}

According to Russell, there is an underlying logic in science waiting to be systematized:

There is ... a logic implicit in scientific practice, but this logic is conformulated. A crude attempt to formulate it was made by G.[sic] S. Mill in his Methods of Agreement, Difference, etc. But his views of causation are not such as modern physicists can accept, nor does causation cover the field of non-demonstrative inference. ("Project", p. 2)

Apparently, Russell is no happier with the current inferential state of affairs in science than he was with the inferential state of affairs in logic and mathematics at the turn of the century. Russell makes several points here: (I) there is a logic implicit in scientific practice, (2) this logic has never been adequately formulated, (3) such a logic, when formulated, must be consistent with current scientific views of causation, ${ }^{1 \mathrm{I}}$ and (4) it must not be limited to causal inferences, since causal inference is only a subclass of non-demonstrative inference. (Presumably, the basis of non-causal inferences must also be consistent with scientific views.) But not all non-demonstrative inference is acceptable, especially the "hasty generalizations" of the untrained.

It is clear, once again, that Russell has a canon in mind. He plans to analyze scientific method to supplement the standards of demon-.

" This implies that the efficacy of the principles of inference is contingent, an anticipation of Russell's views on the postulates in Human Knowledge. (The postulates of inference go back at least as far as 1927; they are discussed in AMa. I thank Francisco A. Rodriguez-Consuegra for this observation.) 
strative inference with standards of non-demonstrative inference. With this more comprehensive canon we will be able to explain, for a much greater class of arguments, what makes them reasonable or unreasonable. The leading problems are parallels to those faced by early Greek mathematicians: (I) to distinguish reasonable from unreasonable nondemonstrative inference; (2) develop a logical theory to explain it; and (3) devise formal or near-formal tests to help us make the distinction in practice. Russell makes it clear that scientific method, for the purpose of this analysis at least, is to be treated as valid, and any attempt to justify it is futile. He notes in passing: "No one, incidentally, has ever demanded a justification of deduction; any such justification would employ deduction, and therefore be circular" (ibid.).

Russell invites us to see the circularity discovered by Hume as a symptom of just how fundamental non-demonstrative inference is. There is the germ of an argument here if we remember that demonstrative inference is a canon of rational argument. To ask for a justifcation of deduction is to ask for a justification of our standards of reasonable argument. Such a justification would be an argument for the reasonableness of deductive argument. Now we can either evaluate this justification or not. If not, we can't tell whether it is reasonable, and won't know whether to accept it. If so, then we evaluate it against some standard, some canon of reasonable argument; but the only canon of argument available is the very deductive logic we are trying to justify. Thus, our justification, presuming we can construct one, will be impossible to evaluate non-circularly. More to the point, the very notion of asking for a justification of the very canon of justification, in the same sense, is incoherent. Once we realize that there is a non-demonstrative canon as well, we should realize, by parity of argument, that to ask for its justification is equally incoherent, and regard Hume's discovery of the circularity involved in justifying induction as a symptom of this incoherence.

While Russell claims that scientific method is unjustifiable he does not claim that our acceptance of its validity should be unqualified, despite his earlier insistence that we have an implicit canon of nondemonstrative inference and his suggestion that its embeddedness rivals that of deduction. First, he qualifies his claim that scientific method should be treated as valid ("In this analysis ..."). Second, he remarks: "Scepticism is excluded by the decision to analyze scientific method rather than criticize it. This decision of course does not bear on the question whether the sceptic is in the right; it merely defines the scope of our inquiry" (ibid., p. 3).

Russell makes it clear that he has not abandoned critical epistemology in favour of a wholehearted "epistemology naturalized". The descriptive project of analyzing the non-demonstrative inferences we have in fact accepted-Russell's project-does not settle, at least in Russell's mind, the critical question of whether we ought to have accepted them. Russell reserves the right to question whether the canon of non-demonstrative inference is truth-conducive, and this critical question may well be raised most profitably after the implicit canon has been systematized and the "accepted" forms of non-demonstrative inference clarified for all to see.

\section{SUMMARY AND CONCLUSION}

Russell suggests that the Humean predicament is a symptom of the clash between our insistence that scientific inference is reasonable and our insistence that all reasonable argument is demonstrative. Since scientific inference is not demonstrative, it is either unreasonable, or not all reasonable argument is demonstrative. There are two basic reasons to accept scientific inference as reasonable and deny that all reasonable argument is demonstrative: (I) we already accept scientific, non-demonstrative inference, in practice, as part of the canon of reasonable argument; (2) the alternative, scepticism, is insincere.

Historically, mathematical logic-our explicit, demonstrative canon of argument-arose from informal mathematical disputation and gradually became systematized. Scientific inference-our implicit nondemonstrative canon of argument-is arising from informal scientific disputation. Its problem is not acceptance-it is as well entrenched as mathematical logic - but obscurity. Thus, at least practically speaking, it needs systematization, not justification.

Philosophically, justification of scientific method, of the demonstrative sort that the sceptic demands, is not possible. Further, the request for a justification of our canon of justification is incoherent. The futility and incoherence of the sceptical request should be seen as a reductio ad absurdum of the sceptical standards of reasonable argument.

Practically, the sceptical request is insincere; no one accepts the 
scepticism that results from insisting on a demonstrative justification of science. Demonstrative and scientific non-demonstrative inferences are supported by widely accepted successes, but the insistence on an exclusively demonstrative canon of inference has been a short road to universally rejected scepticism.

Though the project is primarily descriptive, there is still room for critical epistemology. Not all non-demonstrative inference is acceptable, and the dividing line between reasonable and unreasonable nondemonstrative inference has yet to be drawn. Clarity on this point will come only with systematization, and so the descriptive project of systematizing non-demonstrative inference becomes important for critical epistemology. Russell hints that the critical question of what nondemonstrative inferences we should accept, if any, is not settled by an answer to the descriptive question of what inferences we have accepted.

But if scepticism is uninteresting and sceptics insincere and, in the extreme sense Russell worries about, non-existent, then why not dismiss the sceptic outright? And if scientific non-demonstrative inference is a well-accepted, implicit canon of inference, then why not accept it as "valid" outright? In short, why not simply naturalize epistemology: the insincerity of scepticism would usher out traditional epistemology, and the canonization of scientific non-demonstrative inference would usher in natural epistemology.

Russell, apparently, does not think that either his response to the sceptic or his canonization of non-demonstrative inference constitutes a sufficient philosophic defence of his descriptive program. Let's first consider his response to scepticism, then turn to his canonization of non-demonstrative inference.

First, only a very narrow sort of sceptic has been answered, one who expects us to provide an argument that justifies our standards of argument. Russell may have thought, and rightly so in my view, that this is a rather trivial form of scepticism, and not all varieties of scepticism obviously reduce to it. He certainly hasn't shown that they do. A more sophisticated form of scepticism could arise to undermine our confidence in scientific non-demonstrative inference.

For example, it may be true that a demonstrative justification of scientific inference is futile, true that there is nothing better founded than science to go on, true that we all accept scientific inference. A sceptic can grant all this and doubt that scientific inference is truthconducive or, granting that it has been in the past, doubt that it will remain so. ${ }^{12}$ In this way, a sceptic who accepts that science is the best theory available can recast the traditional problem of induction without obvious insincerity and still doubt its truth. In doubting that science is true, but not that it is the best available theory, this sceptic may still be "in the right".

Second, the critical question of what non-demonstrative inferences we should accept, if any, is not settled by an answer to the descriptive question of what inferences we accept. Inferences to supernatural entities were the norm at one time, and the history of naturalism has been a history of inferences to many kinds of objects, each widely accepted for a time. I think Russell would agree that the conclusions of these inferences are not only dated but false.

The goal of epistemology, as Russell sees it, is truth; and since we have no unproblematic access to it, our inferences are instrumentally valuable as a means to the end of truth. Scepticism tries to show that there is no good reason to believe that our inferences are, or will continue to be, truth-conducive, and so fail to be instrumentally valuable. The proper epistemic reply to the sceptic, it seems, consists in showing, in some sense, that scientific non-demonstrative inferences are truth-conducive, not that, as a matter of historical fact, we accept them as such. edge:

Russell is quite clear about this five years later in Human Knowl-

In seeking the postulates of scientific inference there are two kinds of problems. On the one hand there is analysis of what is generally accepted as valid inference, with a view to discovering what principles are involved; this inquiry is purely logical. On the other hand there is the difficulty that there is, prima facie, little reason to suppose these principles true, and still less to suppose them known to be true. ( $H K_{2}$, p. $\left.42 \mathrm{r}\right)$

If Russell was tempted to think in 1943 that our acceptance of scien-

${ }^{12}$ R. M. Sainsbury makes this point about Russell's postulates in "On Induction and Russell's Postulates", in Rereading Russell: Essays on Bertrand Russell's Metaphysics and Epistemology, ed. C. W. Savage and C. Anthony Anderson (Minneapolis: U. of 
tific non-demonstrative inference as a canon of argument suffices to show that it is epistemically well-founded, it is clear that he rejected this by 1948 .

A clue to another reason for Russell's reluctance to dismiss the sceptic and accept scientific non-demonstrative inference outright lies, I think, in Russell's final description of the main epistemic question:

The main question is: In what circumstances does scientific method allow us to infer the existence of something unobserved from what is observed? It is easy to prove that deductive logic never allows such an inference; it is also easy to prove that without such inferences most of what is accepted as knowledge collapses. ("Project", p. 3; my italics in the first instance)

This is a very old, very important worry for Russell, one he gave a name to in 1919: “... if we attribute significance to groups of symbols which have no significance, we shall fall into the error of admitting unrealities" (IMP, p. I70).

The groups of symbols Russell is concerned with are descriptions, the sense of "significance" he mentions is reference, and the error he worries about is unnecessary and undesirable ontic commitment to unobserved, theoretical entities. As every Russell scholar knows, a major part of Russell's intellectual energy, including the development of the Theory of Descriptions, was devoted to avoiding such ontic commitment, and it is no wonder that he has some qualms about dismissing scepticism entirely. It is one thing to augment our philosophic canon with principles of non-demonstrative inference that will allow us to infer the existence of desirable, unobserved objects. It is quite another to ensure that these same principles will not allow us to infer unnecessary, undesirable objects.

The decision to analyze scientific inference could well reveal principles that we accept but should not, because they encourage inference to unnecessary entities. If we accept scientific, non-demonstrative inference outright, and our epistemology is simply descriptive, we seem to have no grounds for distinguishing between the forms of nondemonstrative inference we have and should have accepted, and those we have but should not have accepted. Russell's own experience with ontic commitment that seemed necessary and turned out to be spurious, and with inference that seemed impeccable and led to paradox, is,
I think, evident here. ${ }^{13}$

Russell's project, envisioned in 1943, and completed in 1948 as Human Knowledge, has many of the features of natural epistemology: the admission that a reply to the sceptic is futile and uninteresting (though this is a qualified claim), that science is to be considered valid (though this too is a qualified claim), that knowledge is fallible, and that the relation between evidence and theory is not strictly logical. However, if Russell contemplated a naturalistic turn in 1943 he did not wholeheartedly take it. The descriptive project of analyzing scientific inference is in the hands of a critical epistemologist whose worries that the sceptic has not been answered adequately and scientific inference has not been adequately grounded epistemically are not far from the surface. In 1943, at least, natural epistemology is contained in critical epistemology. ${ }^{14}$

\footnotetext{
${ }^{13}$ Quine would argue that the traditional question of whether there "really are" the objects we infer, or postulate, is transcendental and unanswerable. The question of whether a given inferred or postulated entiry is necessary or desirable is an "internal", scientific question to be answered by the relative costs and benefits of admitting it. So, Russell's worry about admitting unrealities can be taken care of, if it can be taken care of at all, within a thoroughly naturalistic epistemology.

${ }^{14}$ I would like to thank Albion College for sabbatical leave to work on this and other projects, and Albion's Faculty Development Committee for a small grant to visit the Bertrand Russell Archives. Thanks to archivist Kenneth Blackwell for his generous assistance, to Sheila Turcon, also at the Russell Archives, and to my colleague H. E. Cline, who read an earlier version of this paper.
} 